\title{
Faāliyatu Istikhdām Fīlm Ar-rusūm Al- Mutaharrikah Li At-Tasyjī'At- țullābi Fī Mahārah Al-Kalāmi Bī MAN 2 Langsa
}

\author{
Rusdy Iskandar ${ }^{1}$ \\ ${ }^{1}$ Institut Agama Islam Negeri Langsa \\ ${ }^{1}$ rusdyiskandar0605@gmail.com
}

\author{
First received: \\ 11 October 2021
}

Revised:

Final Accepted:

December 2021

December 2021

\begin{abstract}
Abstrak
Film Animasi adalah salah satu media pembelajaran yang dapat digunakan guru dalam pembelajaran keterampilan berbicara oleh karena itu penulis ingin melakukan penelitian tentang film animasi dan efektivitas penggunaannya dalam pembelajaran keterampilan berbicara di MAN 2 Langsa. Karena media ini belum pernah digunakan di sekolah ini. dengan demikian peneliti ingin menjawab pertanyaan berikut apakah penggunaan Film animasi pada pembelajaran keterampilan berbicara di MAN 2 Langsa efektif? Penelitian ini bertujuan untuk mengetahui efektivitas penggunaan film animasi dalam keterampilan berbicara di sekolah ini. Pada penelitian ini peneliti menggunakan pendekatan kuantitatif dengan metode eksperimen. Populasi penelitian yaitu semua kelas 10 sebanyak 6 kelas dengan jumlah 150 orang. Adapun sampenya adalah siswa kelas 10 MIA $^{1}$ sebagai kelas eksperimen dan $10 \mathrm{MIA}^{2}$ sebagai kelas kontrol. Teknik pengambilan sampel adalah dengan purposive sampling. Peneliti menggunakan teknik pengumpulan data dengan menggunakan observasi, wawancara dan tes awal dan akhir dalam pengumpulan data dan sesudah melakukan penelitian hasil penelitian menunjukkan bahwa penggunaan Film Animasi dalam keterampilan berbicara di MAN 2 Langsa sangat efektif hal ini dibuktikan dengan tes yang dilakukan di dua kelas karena hasil uji t 3,163 lebih besar dari pada 2,021 pada t tabel, maka hal ini menunjukkan bahwa hipotesa diterima.
\end{abstract}

\section{Kata Kunci : Film Animasi Meningkatkan Motivasi Siswa - Maharah Kalam}




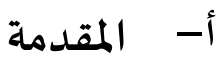

إن التربية هي عملية التي تغير سلوك الناس والدارسين لتكون البشرية في الحياة الحقيقية. تهدف عملية التعلم إلى تزويد المتعلم بقدر مناسب من المعلومات والمهارات والخبرات والنظرياه والعملية في استخدام الوسائل التعليمية وإمداده بكل ما يساعده في

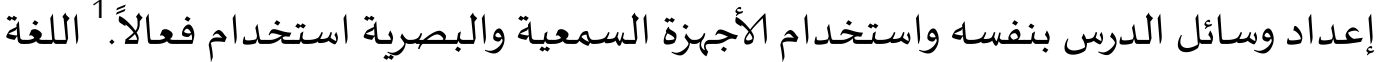
هي الأداة الرئيسية للتواصل في حياة الإنسان. اللغة نافذة على العالم وأداة لفتح مفتاح العلم. اللغة هي أيضًا أداة الاتصال في شكل نظام رمز صوتي ينتج عن كلام الإنسان. سينقل كل إنسان نواياه إلى البشر الآخرين من خلال اللغة. لذلك، اللغة شيء يجب تعلمه وممارسته

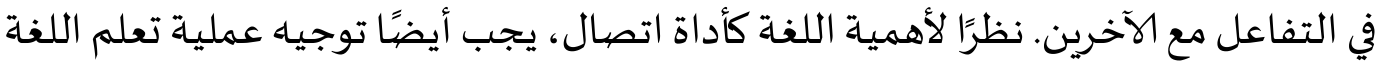

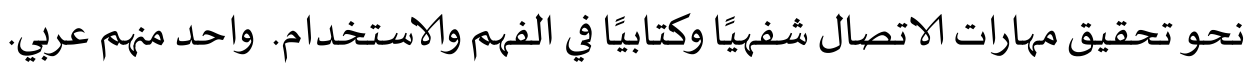

اللغة العربية هي إحدى المواد التي يتم تدريسها في المدارس الدينية في إندونيسيا والتي تعمل كلغة الدين والعلم، بجانب اداة التواصل. نظرًا لارتباطها بالدين والعلم، تعد

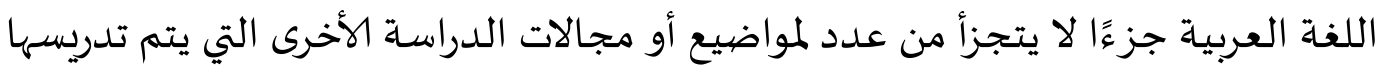

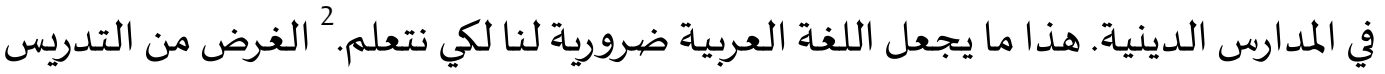
للغة العربية في إندونيسيا هو في الواقع توفير الطلاب لاستخدام اللغات الأجنبية بنشاط وسلاسة. اللغة العربية لها أربع مهارات وهي: الاستماع والكلام والقراءة والكتابة. مهارة وإحدى يجب تحقيقها وهناك حاجة إليها من التعلم العربي هي مهارة الكلام.

إن مهارة الكلام هى مهارة لغوية أساسية يجب أن يجيدها الطلبة. الكلام أيضا نشاط أساسي من أنشطة الاتصال بين البشر، وهو الطرف الثاني من عملية الاتصال الشفوي، والاستماع وإذ كان الاستماع وسيلة لتحقيق الفهم، فإن كان الكلام وسيلة

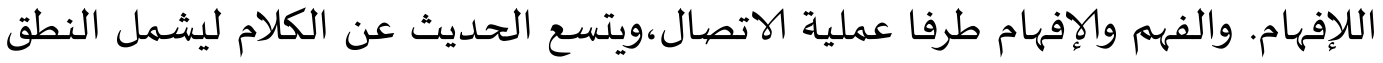

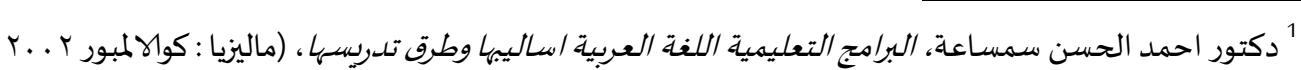

$$
\begin{aligned}
& \text { م)، ص. THO }
\end{aligned}
$$
Gaung Persada Press, 2007), h. 1 
الأصوات والمفردات والحوار والتعبير الشفوي.3 الحديث هو الأنشطة اللغوية المهمة في

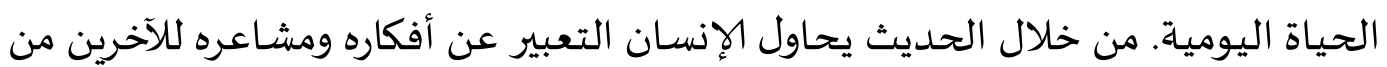

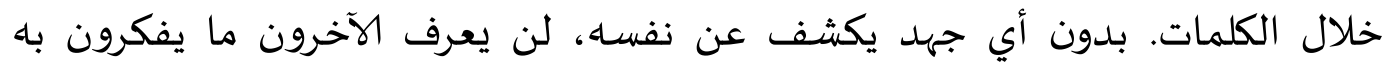

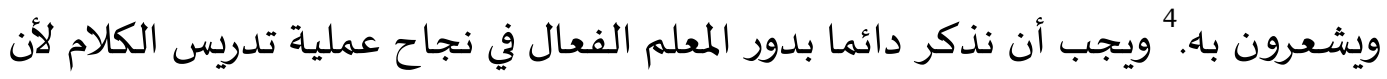

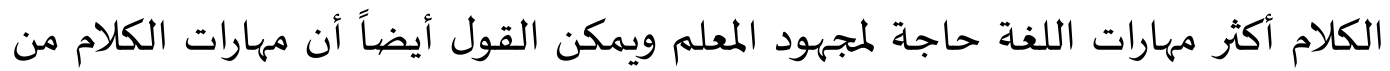
مهارات التي يتحمل المعلم في تنميتها عباء كبيراً.

إن الكلام هو المهارة الإنتاجية الثانية، والمهارة الرئيسية في تعليم اللغة. لكن في

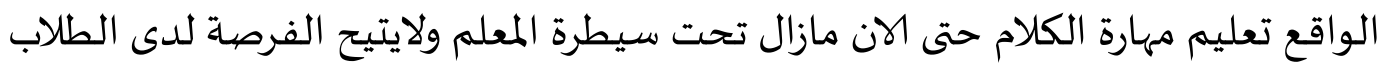

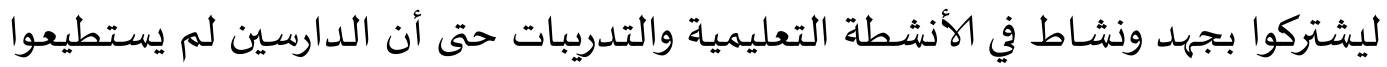
أن يتكلموا باللغة العربية ويشعرون بالملل في تعلم اللغة العربية. وقد ذكر محمد عبد العدان

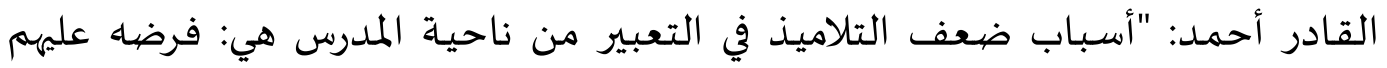
الموضوعات التقليدية الضيقة وعدم تركه الحرية للتلاميذ في اختيار الموضوع، وحديثه

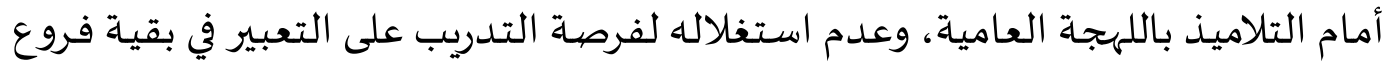

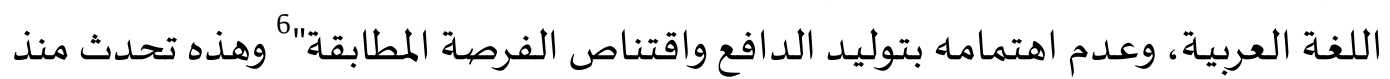
عصر القديم حتى عصرنا الحاضر.

استناداً إلى الملاحظة التي أبداها الباحث بـ MAN 2 LANGSA، تبينت أنه ليس

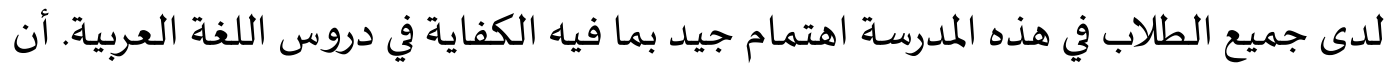

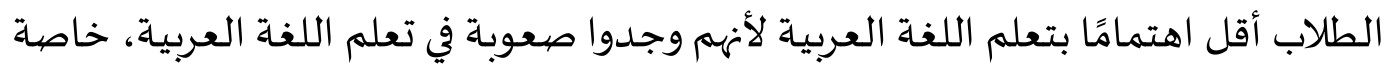

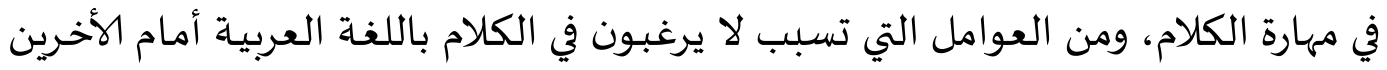

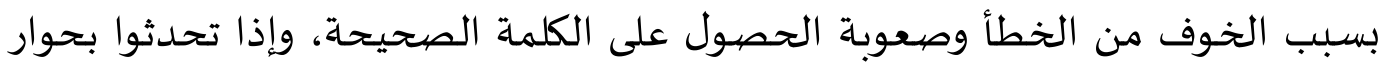

33 دكتور رشدى أحمد طعيمة, المهارات اللغوية مستوياتها, تدريسها, صعوتها, القاهرة : دار الفكر العربي. 1425هـ.2004م, ص. 185

${ }^{4}$ Nur Balqis dan Meutia Rahmah, Media pembelajaran bahasa Arab. Langsa: Percatakan data printing, hal 43

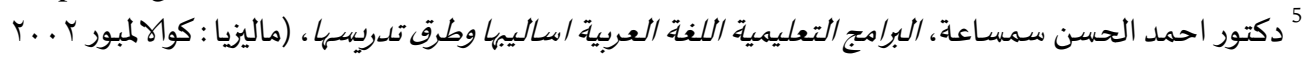

$$
\begin{aligned}
& 6 \text { محمد عبد القادر أحمد، طرائق تدردس اللغة العربية، ط.1، (دمشق: منشرات جامعة دمشق، 1989)، ص: } 225 .
\end{aligned}
$$


تحدثوا بغير طلاقة. وهذه الحالة هي التي تؤدي إلى التكاسل عند الطلبة في تعلم العربية

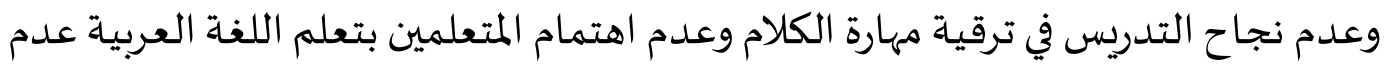
وجود تباين في استخدام المعلمين لوسائل الإعلام التعليمية. عدم وجود وسائل تعليمية إبداعية ومبتكرة تجعل الطلاب يشعرون بالملل وأقل حماسا عند تعلم اللغة العربية.

وإحدى الطريقة لحل المشكلة هو الاستفادة وسائل الإعلام في عملية التعليم ليكون جو التعلم متعاة ويمكن أن تحفز نمو الطالب التعلم الدافع. ومن وسائل التعلم

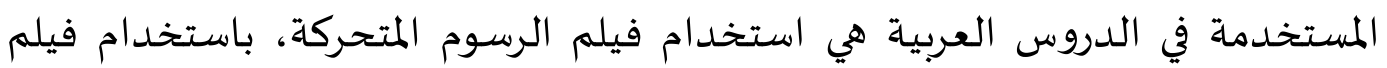
الرسوم المتحركة يمكن للمعلمين شرح وعرض الصهور وأشرطة الفيديو والكتابات المثيرة للاهتمام بحيث يكون الطلاب متحمسين للتعلم والتحفيز في دروس اللغة العبية مهارة

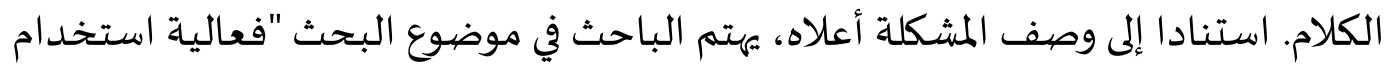
فيلم الرسوم المتحركة لتشجيع الطلاب في مهارة الكلام MAN 2 Langsa

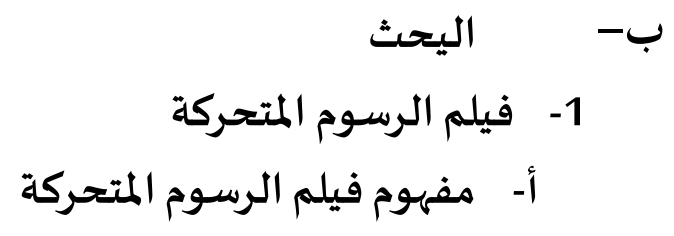

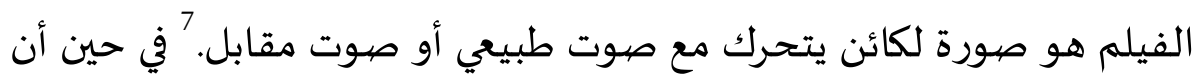

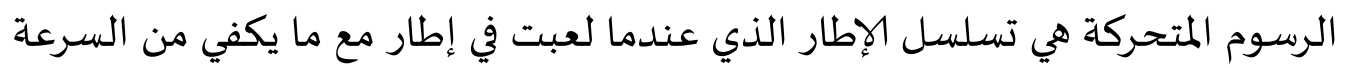
يمكن أن تقدم صورة متحركة على مثل فيلم أو فيديو. 8 فئل

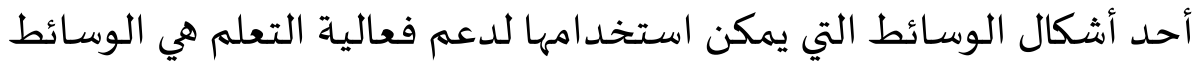

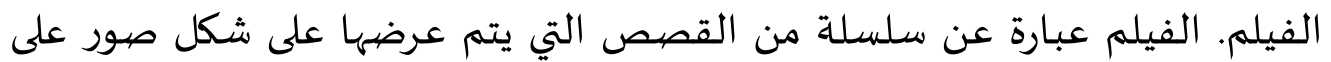
شاشة بيضاء مصحوبة بحركات الممثلين. يتم تقديم المواد الإعلامية بشكل أكثر جاذبية

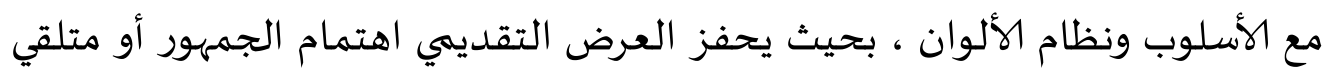

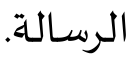

${ }^{7}$ Azhari Arsyad, Media Pembelajaran, (Jakarta: RajaGrafindo, 2009), hal.49.

${ }^{8}$ Yudhi Munadi, Media Pembelajaran, ( Jakarta: GP Press Group: 2013), hal. 127. 
الرسوم المتحركة هي عبارة عن أشرطه تسحيل صورى يتم تصوير خاصة وتكون الصور فيها تابية كما هو الحال في أشرطة السينمائية ويتم عرضها بالتلفاز بوسطة جهاز الفيديو الذي سيأني الحديث عنه لاحقا وأصبح بالإمكان تحويل محتواهيا

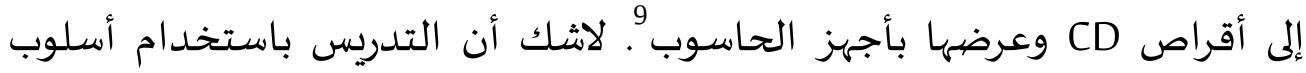

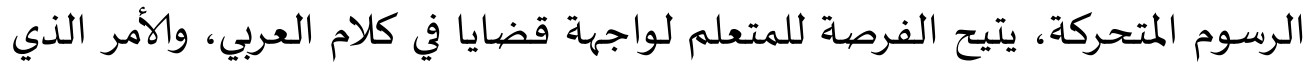

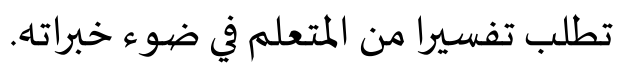

وفوائدها الفيلم للوسيلة التعليمية فوائد عديدة لكل من المعلم والمتعلم وعملية

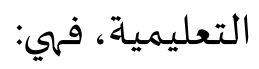

1) الفيلم والفيديو يمكن أن تكمل الخبرات الأساسية للطلاب عند القراءة

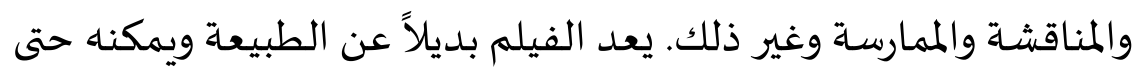

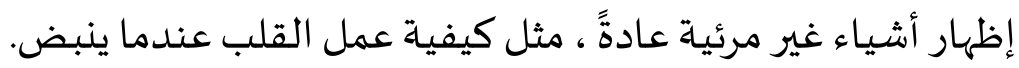

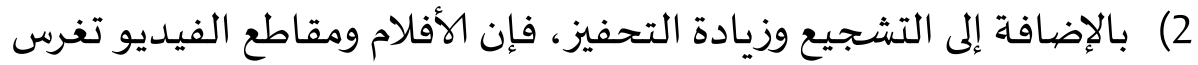

$$
\text { المواقف والجوانب العاطفية الأخرى. }
$$

3) الفيلم والفيديو التي تحتوي على قيم إيجابية أن تدعوا إلى التفكير والمناقشة في مجموعات الطلاب. في الواقع، يمكن للأفلام ومقاطع الفيديو، مثل الشعارات التي تُسمع كثيرًا، أن تجلب العالم إلى الفصل المعل الدراسي. 10

$$
\text { 2- مهارة الكلام }
$$

الكلام في أصل اللغة عبارة عن الأصهوات المفيدة هو المعنى القائم بالنفس فارد

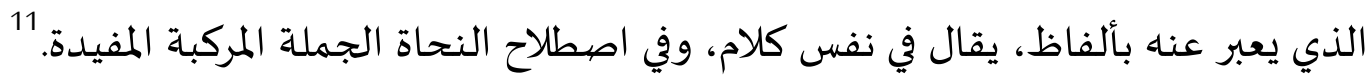

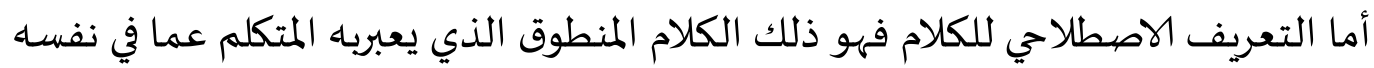

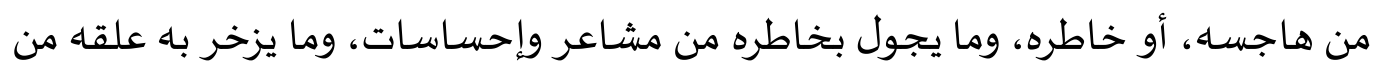

9 محسن على عطية، تكنولوجيا التصال في التعليم الفعال، (بغداد: دار المناهج لنشر والتوزيع) ص، 129

${ }^{10}$ Azhar Arysad, 2007. Media Pembelajaran, (Jakarta : Raja Grapindo Persada, 2000) h. 48

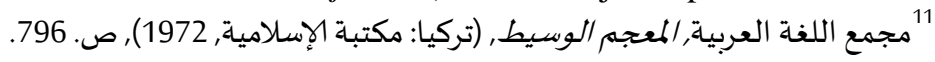


رأي أو فكر، وما يريد أن يزود به غيره من معلومات، أو نحو ذلك، في طلاقة وانسياب، مع صحة في التعبير وسلامة في الأداء. 12 الكلام أيضا نشاط أساسي من أنشطة الاتصال بين البشر، وهو الطرف الثاني

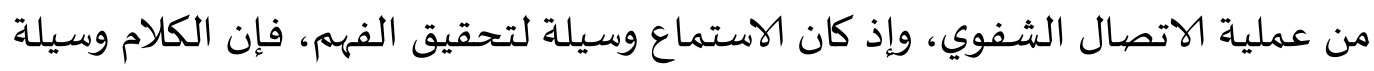

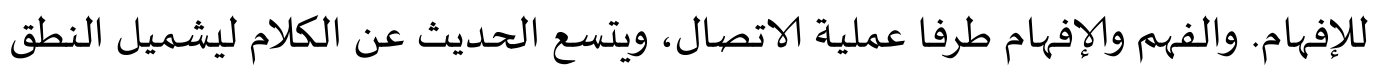

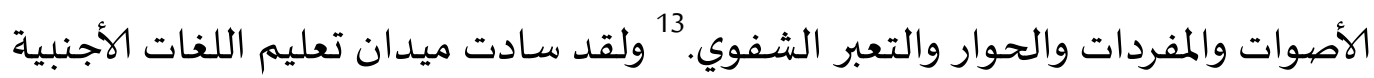
أفكار معينة تركت صداها في عملية تدريس الكلام، وكان كثير من هذه الأفكار خاطئًا

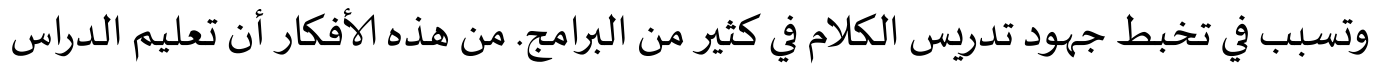
كيف يطرق سؤالا وكيف يجيب عليه مهارتان كفيلتان بتنمية قدرته على الكلام.

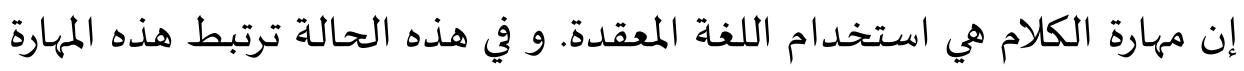

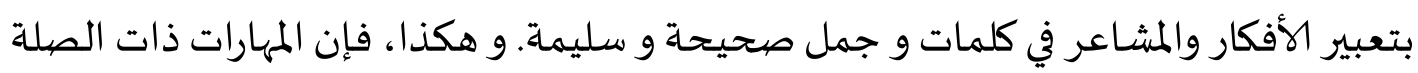

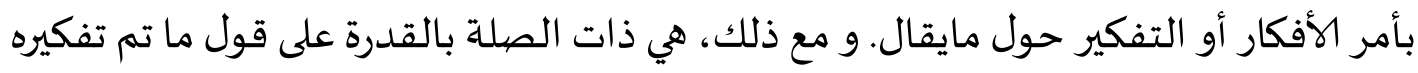

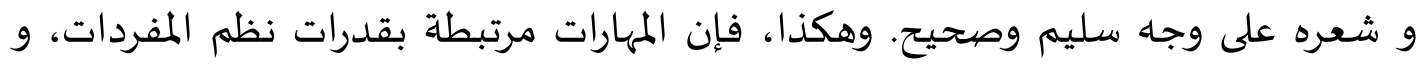
النحوية و الدلالية، والحكيم السليم للصيوت. و كل القدرات تتطلب إلى زاد من الكلمات و

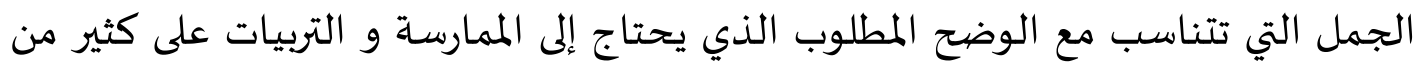

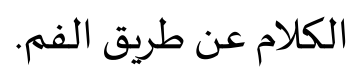

والكلام من أهم وسائل لأجل بناء التعارف و الاتصال الإيجابي بحيث تستخدم

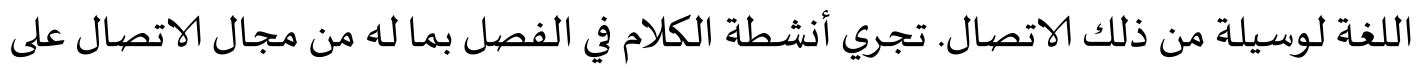

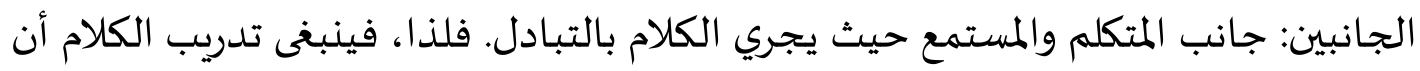
يجري على الترتيب التالي هو الأول، القدرة على الاستماع، ثم القدرة على النطق، والأخير القدرة على المعرفة عن المفردات و أنواع الجمل. 14 ب. اهداف مهارة الكلام hlm. 82 .

$$
\begin{aligned}
& \text { 12 محمد صالح الدين، تدليس اللغوية العببية بالمرحلة الإبتدائية, (الكويت: دار القلم, 1980), ص. } 233 .
\end{aligned}
$$

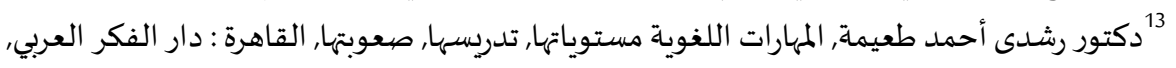

$$
\begin{aligned}
& \text { 1425هـ 2004م, ص.185 دكنو } \\
& { }^{14} \text { Ahmad Fuad Effendi, Metodologi Pengajaran Bahasa Arab, (Malang: Misykat, 2005), }
\end{aligned}
$$


وأما أهداف مهارة الكلام عند دكتور فتحى علي يونس و دكتور محمد عبد الرؤوف الشيخ فهي: أن ينطق الأصهوات العربيّة نطقا صحيحا، أن يميّز الأصهوات المتشابهة نطقا، أن يميّز الحركات الطويلة و الحركات القصيرة، أن يستخدم التراكيب العبيّة الصحيحة الصيّة

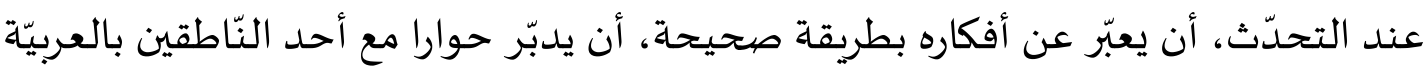
ويدبّر حوارا موضوع معيّن. وأمّا أهداف التعليم مهارة الكلام هي: أن ينطق المتعلم أصهوات اللغة

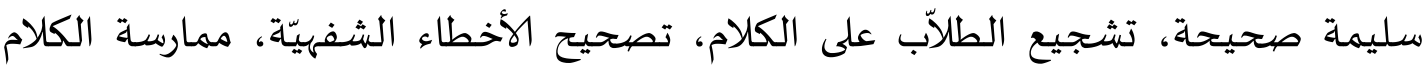
بالعربيّة. 15

$$
\text { من أهم أهداف تعليم الكلام ما يأتي } 16
$$

1- نطق المتعلم أصوات اللغة العربية نطقاً صحيحاً.

2- أدية أنواع النبر والتنغيم المختلفة بطريقة مقبولة من أبناء اللغة.

3- التمييز عند النطق بين الأصوات المتشابهة تمييزاً واضحاً

4- التمييز عند النطق بين الحركات الطويلة والقصيرة.

5- التعبير عن الفكر تعبيراً واضحاً ومفهوماً في مواقف الحركات الحديث البرة البسيطة،

$$
\begin{aligned}
& \text { باستخدام النظام الصحيح لتركيب الكلمة في العربية . } \\
& \text { 6- نطق الأصوات المتجاورة نطقاً صحيحاً. }
\end{aligned}
$$

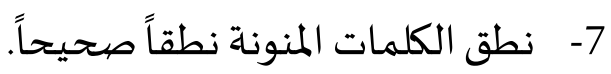

8- أن يكتسب المتعلم ثروة لفظية كلامية مناسبة لعمره وحاجته وأدواره

$$
\text { وخبراته، ويستخدم هذه الثروة في إتمام عمليات الاتصال }
$$

9- أن يفكر المتعلم باللغة العربية، ويتحدث بها بشكل متصل ومترابط لفترات

$$
\text { زمنية مقبولة }
$$

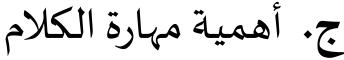

15 فتحي علي يونس و عبد الرؤوف الشيخ, الممرجع في تعليم اللغة العببية للأجانب (القاهرة: دار مكتبة و هيبة، 2003)، ص. 63.00 16 سعيدة عمر محمد ثاني, تنمية مهارة الكلام Vol.21 SUST Journal of Linguistic And Literay Studies مأخوذ في 2010 
يعتبر الكلام الفن الثاني من فنون اللغة الأربعة بعد الإستماع. و هو ترجم

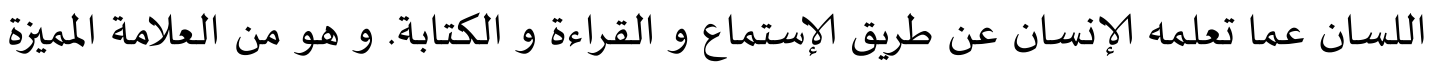

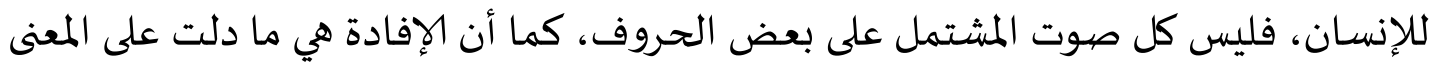

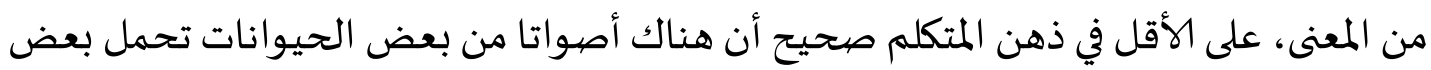

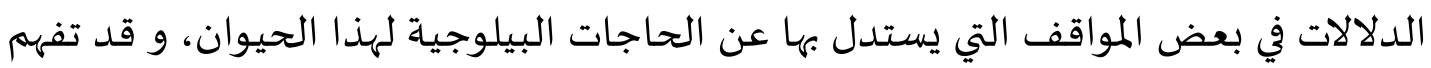

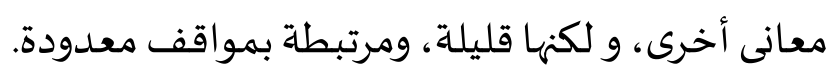

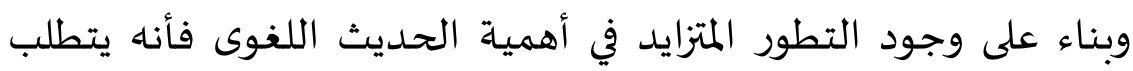
دراسة نظام القوعد اللغوية واصولها، و معاجمها.و واقع الإتصال اللغوي بين الناس يؤكد إن مهارة الحديث تنمو اولا من الإتصال باللغة و يقتضي هذا تشجع المتعلمون على أن يعبروا بأنفسهم أساليب البسيطة. ولا شك أن الكلام من أهم ألوان النشاط اللغوي للكبار والصغار على السواء، فالناس يستخدمون الكلام أكثر من الكتابة في حياتهم. أي أههم يتكلمون أكثر من مما يكتبون. ومن هنا الشكل الرئيسي للاتصال اللغوي بالنسبة للإنسان. وعلى ذلك يعتبر الكلام

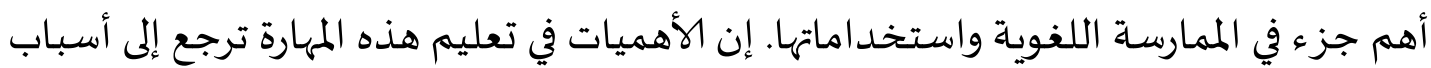
كثيرة منها، لأن اللغة العربية تدور دورا كبيرا في مجال الإتصال الدولي.

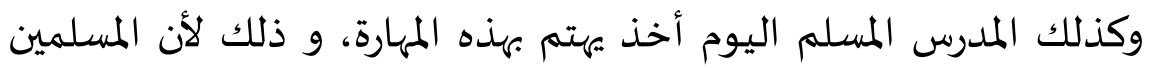
يواجهون المشكلات عندما تنازلهم الدعوة إلى الاشتراك في مسابقة الخطابة المنبرية باللغة العربية. فلذا، تفضل المدرسة معلماذا كفاءة في هذه المهارة. و بالحقيقة أن أهمية هذه المهارة غير مختصرة على ذلك و لكن تشمل دائرة أهميتها إلى مساعدة الطلاب استذكار المفردات أثناء

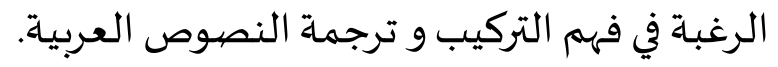

$$
\text { د. دجالات الكلام متعددة، مهارة الكلام مسيذكر الباحث أهم مجالات الكلام وهي كما يلي } 18
$$

17 17رهيم محمد عطا, طريق تدريس اللغة العببية و التويوية الدينة, (القاهرة: مكتبة النهضة المصرى), ص. 106-105.

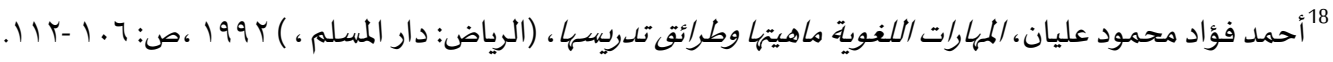


القصة حكاية نثرية تستمد أحداثها من الخيال أو الواقع أو منهما معا وتبنى

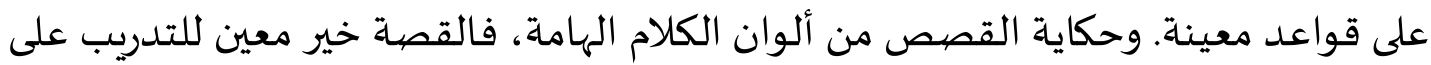

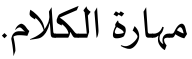

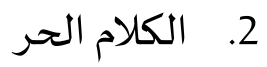

يقصد بالكلام الحر هو التعبير عن الأفكار والآراء الشخصية، وهذا يشمل موضوعات متعددة ومواقف مختلفة، مثل الحديث عن الأمور الدينية، والعادات والتقاليد، والحديث في النوادي الرياضة والثقافية والحفلات، ووصف الأحداث الواقعية

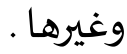

وهذا المجل يعطى الحرية الكاملة للمتكلم كي يعبر عن رأيه، ويشارك في

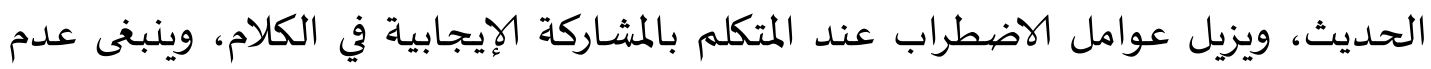
إحراج المتكلم، أو قطع حديثا، أو السخرية منه، أو تخطئة رأيه دون دليل.

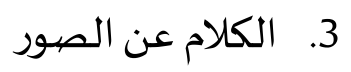

الكلام عن الصور مجال هام من مجالات الكلام الذي يميل إليه الصغار

والكبار. والغرض منه انتقال الذهن من الصور إلى العبارات والألفاظ التي تدل عليها. فالصور منها ما هو متحرك، ومنها ما هو ساكن. فالصور المتحركة مثل أفلام (التلفاز، الفيديو،

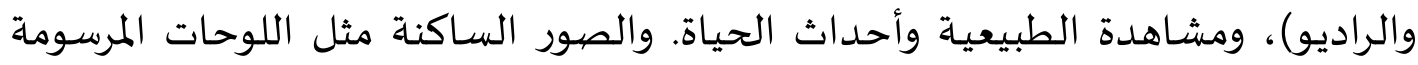
لمناظر طبيعية، أو لأفراد، أو لحيوانات، أو لنبات. ومثل بعض مشاهدة الطبيعية الساكنة، كالجبال والصحراء والبحر وغيرها. 4. - 4. المحادثة

المحادثة مصدر حادث وتعنى أن يشارك شخصيان أو أكثر في الكلام عن المنان

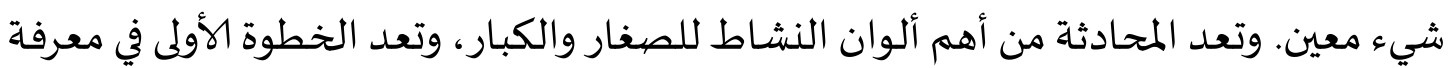
اللغة العربية ـ ولتشجيح الأفراد على المحادثة يحسن أن يكون هناك فرص متاحة لتحقيق نوع

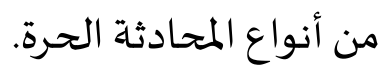




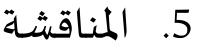

المناقشة مصددر ناقش، ويقصديها الحديث المشترك الذي يكون فياه مؤيد ومعارض،

وسائل ومجيب. والأساس في المناقشة أنها نشاط لإثارة التفكير الناقد، والمفهوم من المناقشة

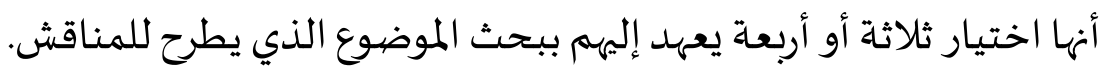

$$
\begin{aligned}
& \text { 6. الخطب والكلمات }
\end{aligned}
$$

يعرض للإنسان كثير من المواقف التى تتطلب منه إلقاء كلمة، فهناك مواقف

التهنئة، ومواقف التعزية، ومواقف تقديم الخطباء والمحاضرين، وحفلات التكريم و غير ذلك.

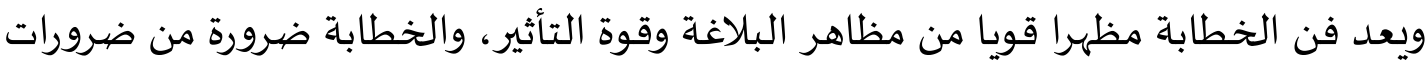

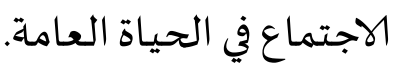

\section{هـ خطوات تطبيقها}

في صياغة فيلم الرسوم المتحركة الخطوات تطبيقها هي:

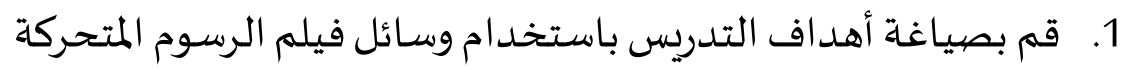

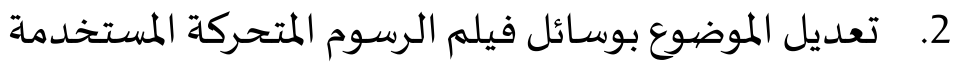

3. لتحضير للفصل، يجب تحضير الطلاب والفصل قبل الدروس باستخدام

وسائل فيلم الرسوم المتحركة.

4. يقوم المعلم بإعداد الأدوات والمواد لوسائل فيلم الرسوم المتحركة

5. طلب المعلم من الطلاب إعداد الكتب. والقرطاسية وغيرها من المعدات

$$
\text { الضرورية. }
$$

6. قم بترتيب مقعد الطلاب بحيث يمكن لجميع الطلاب أن يروا ويسمعوا

جيدًا.

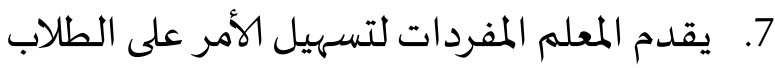

8. - ميعرض المعلم الفيلم على الطلاب

${ }^{19}$ Bobbi Deporter, et al, Quantum Teaching Mempratekkan Quantum Learning di Ruang ruang Kelas, terj, Ari Nilandari (Bandung : Kaifa, 2008), h. 70 
9. ثم سأل المعلم شفويا ما هو عنوان الفيلم، من هو ممثلة، كيف يجري

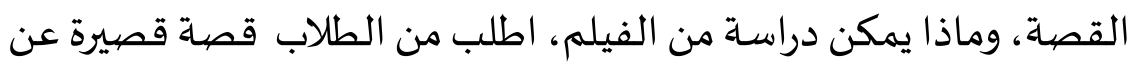

$$
\text { و. تحليل البيانات وتفسيرها }
$$

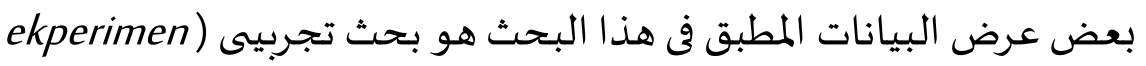

research . يهدف لمقارنة العلاقة القوية بين المتغيرات. وهذا البحث يعتمد على أسلوب تحليل البيانات لهذا البحث هو الإحصاء الاستدلالي. وتقوم الباحث بالإختبار -ت (t-test). ${ }^{21}$ وهذه الاختبار لمعريفة فرق النتيجة بين المجموعة التجربية والضابطة. وقد عرضت الباحث في الجدول السابق، ثم قام الباحث بإدخال النتائج السابقة إلى الرمز الاحصائي t-test. في حساب

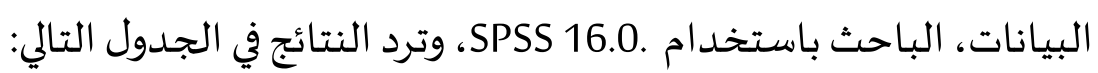

Group Statistics

\begin{tabular}{|l|r|l|l|l|l|}
\hline & Kelas & \multirow{2}{*}{$\mathrm{N}$} & \multicolumn{1}{|c|}{ Mean } & \multicolumn{1}{c|}{$\begin{array}{c}\text { Std. } \\
\text { Deviation }\end{array}$} & \multicolumn{1}{|c|}{$\begin{array}{c}\text { Std. Error } \\
\text { Mean }\end{array}$} \\
\hline hasil & 1 & 20 & 85.50 & 10.625 & 2.376 \\
& 2 & 20 & 76.75 & 6.340 & 1.418 \\
\hline
\end{tabular}

Independent Samples Test

\footnotetext{
${ }^{20}$ Nur Balqis dan Meutia Rahmah, Media pembelajaran bahasa Arab. Langsa: Percatakan data printing, hal 49

${ }^{21}$ SuharsimiArikunto, Prosedur Penelitian, Pendekatan Praktek, (Jakarta : Rinekha Cipta, 2002), h.112
} 


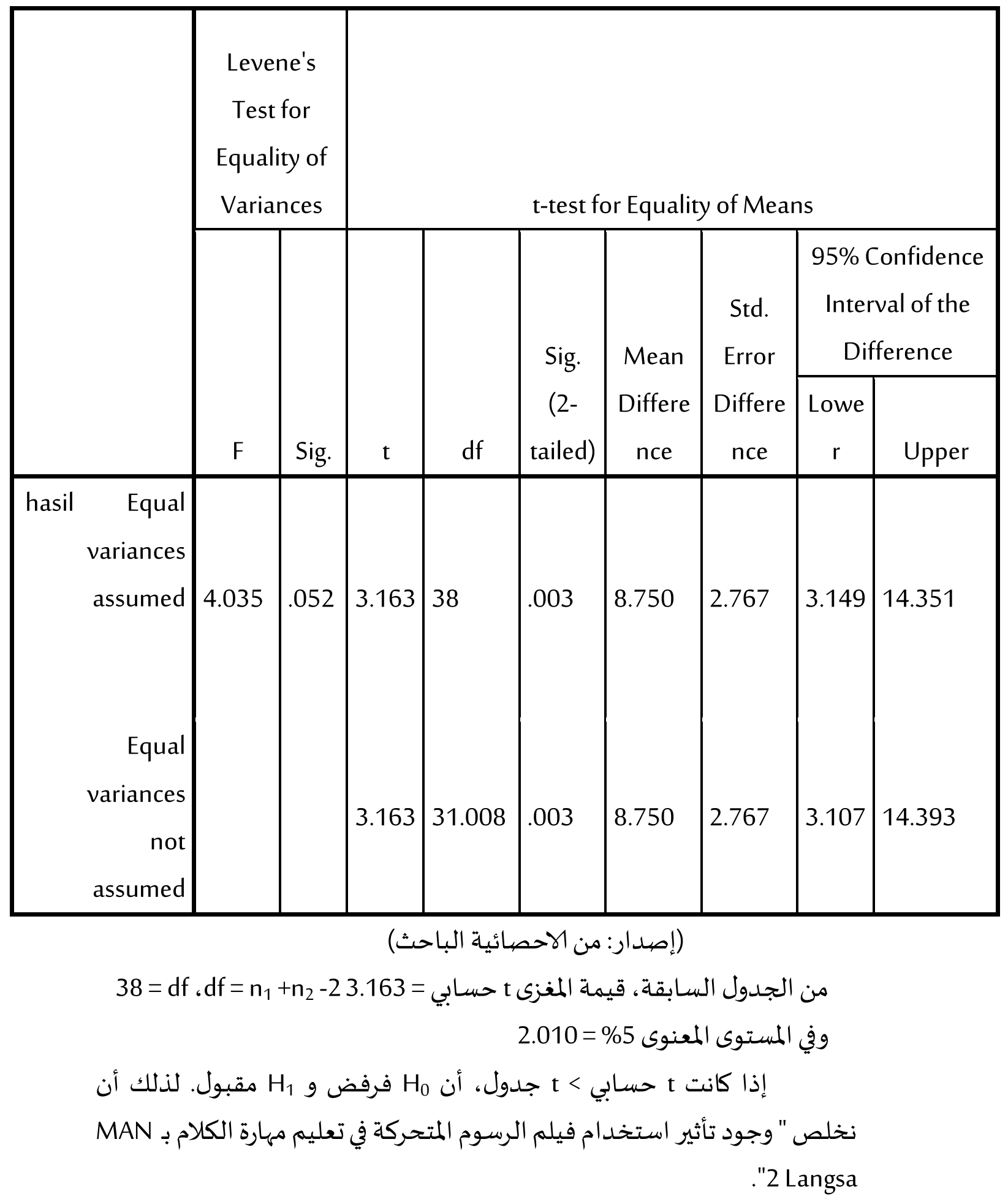


بالنظر إلى نتائج الاختبار القبلي و الاختبار البعدي التي حصل علهها الطلاب،

$$
\text { فنتائج هذا البحث هي فيما يلي: }
$$

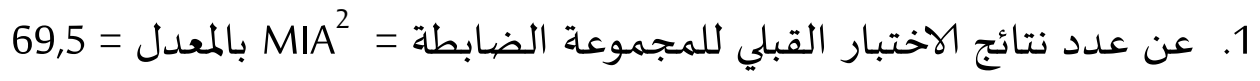
وأما نتائج الاختبار القبلي للمجموعة التجبريبية = MIA

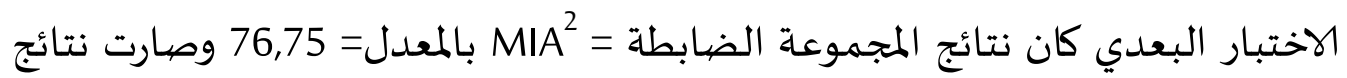

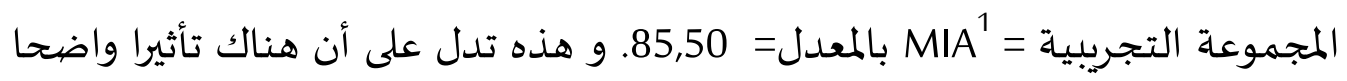
بعد استخدام فيلم الرسوم المتحركة للمجموعاة التجريبية، وذلك لأن نتائج الاختبار

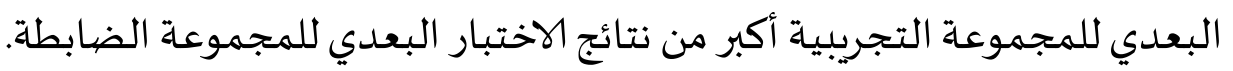

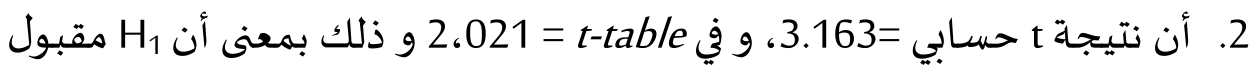
أي أن فروض هذا البحث مقبولة. وخلاصتها أن استخدام فيلم الرسوم المتحركة تأثيرا في تعليم مهارة الكلام.

وتلك النتائج تدل على أن الاستجابات الإجابية من المجموعة

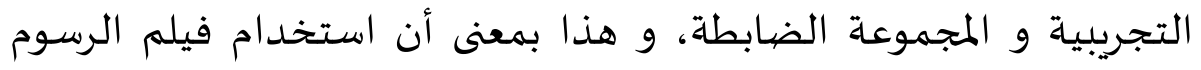
المتحركة تؤثر في تعليم مهارة الكلام.

$$
\begin{aligned}
& \text { ز. نتائج البحث } \\
& \text { بعد تحليل البيانات وصل الباحث الى اهم النتائج الآتية: }
\end{aligned}
$$

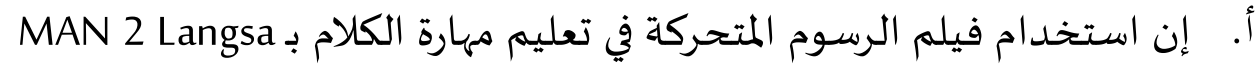

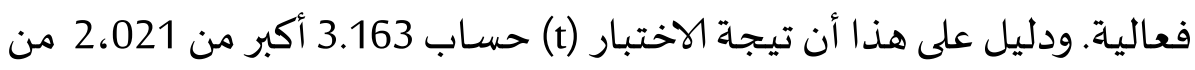

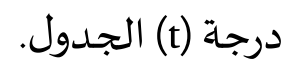

ب. إن قدرة الطلاب في تعليم الكلام مرتفع بإستخدام فيلم الرسوم المتحركة بـ MAN 2 Langsa أكبر من نتيجة الإختبار البعدي في المجموعة الضابطة. 
أحمد فؤاد محمد عليان. 1992. المهارة اللغوية ما هيتها وطرائق تدريسها. رياض: دار المسلم للمتشر والتوزيع.

دكتور احمد الحسن سمساعة. ؟ ..r. البرامج التعليمية اللغة العربية اسالييها وطرق تدريسها. ماليزيا : كوالمبور

طعيمة، رشدي أحمد. 2004. المهارات اللغوية مستوياتها، تدريسها، صعوبتها. القاهرة : دار

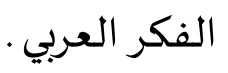

عطا، ابرهيم محمد. 1991. طريق تدريس اللغة العربية و التربوية الدينة. القاهرة: مكتبة الهضية المصرى. مجمع اللغة العربية. 1972. المعجم الوسيط. تركيا: مكتبة الإسلامية. محسن على عطية. 2008. تكنولوجيا الاتصال في التعليم الفعال. بغدادئ داديه دار المناهج لنشر والتوزيع

يونس، فتحي علي وعبد الرؤوف الشيخ. 2003. المرجع في تعليم اللغة العربية للأجانب. القاهرة: دار مكتبة و هيبة.

Faisal Hendra dkk, , 2007. Kemampuan Berbahasa Arab Siswa Madrasah Aliyah . Cet. I ;Jakarta: Gaung Persada Press.

Nur Balqis dan Meutia Rahmah, Media pembelajaran bahasa Arab. Langsa: Percatakan data printing

Azhari, Arsyad, 2009. Media Pembelajaran. Jakarta: RajaGrafindo 